\title{
AN INVESTIGATION OF THE ASPECTS THAT AFFECT THE QUALITY OF REVITALIZED PUBLIC SPACES With special reference to the city of Colombo, Sri Lanka
}

\author{
LANKADHIKARA L.R.M.N.L. ${ }^{1} \&$ RATNAYAKE G.R. ${ }^{2}$ \\ ${ }_{1,2}$ Dept. of Town \& Country Planning, Faculty of Architecture,University of Moratuwa, Moratuwa, Sri Lanka \\ Nadeeshalakshani96@gmail.com
}

\begin{abstract}
Public spaces are the places where all people can come together and spend their time without any restriction and it can be defined as the "City Living Room". Therefore, these spaces can foster social cohesion, reduce psychological stress and provide physical activities. Public spaces have unique historic and architectural values and such places can be used to enhance the place making character of the area. Planning agencies often use revitalization, restoration, regeneration, refurbishment or redevelopment as Placemaking tools which can improve the quality of such public spaces in a city. It is often acknowledged that "revitalization" can be identified as one of the viable alternatives instead of demolition of historical buildings. "Revitalization" and "Adaptive re-use" can be identified as the tools for creating public spaces which are livable, accessible and convivial places for all. The previous studies have researched on the aspects an essential method to make places functional, attractive and convivial spaces. Although researchers studied the general functional aspects of revitalized public spaces, a few studies have focused on the quality and the barriers for such revitalized public spaces. This study attempts to fill this research knowledge gap and investigates what are the barriers and areas that need to be improved in the revitalization process within the Sri Lankan context by using three case studies in Colombo. As our framework of this study, we used access \& linkages, comfort \& image, uses \& activities to assess the quality of revitalized places. This study further found that barriers associated with the process of revitalization are regulatory, social barriers, and technical barriers.
\end{abstract}

Keywords: Adaptive Reuse, Barriers for revitalization process, Placemaking, Public spaces

\section{Introduction}

In 1961, Jane Jacobs, in her book 'Death, and Life of Great American cities' notes, "cities have the capability to provide something for everybody, only because, and only when, they are created by everybody". This emphasizes that cities are for people and they are inclusive entities for all. Car(1992) suggests that to bridge the connection between people and places "public spaces are important because they provide avenues for movement, a means of communication and a common ground for enjoyment and relaxation." Well managed and designed revitalized spaces arouse people's sense of place, identity and sense of belonging. The idea of revitalization is to balance the current rapid development in the urban context through conserving the city's identity, culture and historical legacy. Urban revitalization (UR) is one of the sustainable planning attempts to create better cities for people and make better public spaces. This research aims to investigate what attributes should be considered as the quality of revitalized urban public spaces through people's perceptions and their experiences. At the same time, it is going to have a look on what are the barriers and things that need to be improved within the Sri Lankan Revitalization process.

Therefore, previous researchers have identified the importance of revitalized public spaces. Authors have shown that public space revitalization programs have brought intercultural communities together and such spaces reflect the social life and interaction of people. Some have argued that revitalized spaces in the city generate sense of place and sense of community. In the Sri Lankan context, a few Sri Lankan research have been investigated on impact of historical buildings on real estate 
development in Colombo and urban renewal aspects associated with revitalization programs in Colombo and policies, issues of such developments. It appears that a little research has been focused on the users' perceptions and experiences on the quality of revitalized public spaces and the barriers towards these revitalization projects. So that the main objective of this study is to investigate the quality of revitalized public spaces through user perceptions and their experiences while identifying the barriers or the challenges for revitalization process in the Sri Lankan context. Therefore, three case studies have been selected which are well known and popular among local and foreign visitors: Arcade Independence Square(AIS), Dutch Hospital Colombo (DH) and Race Course Playground (RC). In considering the research gap, the central research questions of this study are,

1) How people perceive and what are their experiences and perceptions on the quality of revitalized urban public spaces?

2) What are the barriers that can be identified in the Sri Lankan process of Revitalization? Are the two research questions that are going to investigate through this research study.

\section{Literature Review \& Similar studies}

Public spaces can be defined as the 'city living room' because those are the places where every human being comes and spends their leisure time together. According to Cousseran, Public spaces have also been identified as 'theatrical stages' in the city. Public spaces act as a catalyst for cities' development to enhance the quality of life, sense of place and place attachment. Public spaces have many types and forms in terms of usage and physical appearance. Revitalized public spaces can be identified as one of such public spaces in cities. According to the authors point of view, Revitalized public spaces reveal the past glory in a novel way that depicts the changing needs of the community and their preferences by considering the best fit use for that urban space while preserving its historical cultural legacy for the next generation to feel it with modernity.

Therefore, to preserve the historical and cultural legacy of such revitalized urban public spaces there need to have 'Place quality' and 'sense of place'. These two important aspects to be considered to improve the user satisfaction and the functionality of that particular place. These spatial qualities have been discussed in sensory urbanism theory (SU) which attempts to conceptualize revitalized spaces in a more holistic approach. It provides a framework to measure the quality of urban spaces in relation to the wellbeing of people. It recognizes that people are the main factor that guides our use of space, social norms and unwritten rules that influence our behavior as well as our bodily experience of space. In this line of thinking, the SU approach mainly considers three components such as perception, cognition, and emotion. Accordingly, peoples' perceptions and the experiences will be increased with the way of usage and the design of a particular place. Considering the literature, similar ideas can be found in place making theory also.

In a similar vein, Placemaking theory is one of the successful development mechanisms which could convert these urban voids to strong elements within the urban fabric rather than using them for dumping debris. It mainly focuses on the people and places and how peoples' perceptions affect the use of a place. It is a human-based approach in urban planning and finds out the path towards making sustainable urban spaces in the city (Donovan,2017) It has been identified as a powerful tool in achieving sustainable goals and it is used as a city design guideline for many countries around the world as their development guide plans. There are different types of Placemaking approaches such as strategic, creative and tactical Placemaking. With the Placemaking theory, ideas on sense of place (SOP), place attachment and the quality of place (QOP) also shed some light to assess the different perceptions in relation to revitalized public spaces in a city. SOP mainly focuses on three things; cognitive, behavioral, and emotional senses towards a place and the place attachment and it also considers eight factors such as physical, social, cultural, personal, memories and experiences, place satisfaction, interactions and activity features, and time factor. SOP also provides some thoughts as peoples' memorable experiences can be identified in revitalized public spaces in terms of three aspects such as place quality, social opportunities and the physical form. Building on this line of thinking, past scholars have identified other aspects that should be represented to create pleasant or unpleasant memorable experiences of people related to a place. In this backdrop, it is worth noting the concept of quality of place (QOP) which can also be used to evaluate revitalized public spaces. A quality can be defined as an attitude towards a place that was acquired over some time after having multiple experiences in that place (Baker \& Crompton, 2000, p.787). Place quality can be evaluated by using some parameters such parameters or the criteria have been identified by many scholars. According to the Project for Public Space (2000), in this study they have provided valuable key attributes after doing lot of surveys on public spaces and the users perceptions they have identified these four attributes such as comfort \& 
image, access \& linkages, uses \& activities and sociability. These four attributes can be used to evaluate the quality of a public space. In that line of thinking, within this study it is aimed to evaluate the quality of revitalized public spaces by using those four attributes:

01) Comfort \& Image: Public spaces are the places where the people spend time to carry out recreational activities using the existing facilities. Moreover, activities, facilities are the two main things that enhance the livability of a place. Comfort can generate good and positive image perceived by the users (Lynch, 1960). Therefore, in this study, comfort can be measured through the level of satisfaction towards to the existing facilities within these revitalized public spaces and image of a place is another important attributes need to have a look. The image will be investigated through users' memorable experiences related to selected case study areas with Photo-voice survey.

02) Access \& Linkages: public spaces are the inclusive for all people regardless of their gender,age or social strata. Therefore, those places should be as open as possible. As a result of that, access and linkages is very important to connect people with public spaces. Some studies have emphasized that public spaces are the places where all people have access to variety of activities.

03) Uses \& Activities: public spaces are not only for meetings and gatherings but more than that those places can provide vitality of activities and different types of uses. These activities or the uses can make the places alive, unique and enhance its identity directly or indirectly.

04) Sociability: this attribute is difficult to achieve but must be there in a successful public space. Because, the core of public spaces is "people" and public spaces need to be encouraged its users to come and engage with different activities while creating affection and strengthening social interaction and improve their social networking with other users. Finally this will lead to have positive impacts when creating sociability within the public spaces itself. Considering the above four aspects together with the past literature, the current study analytical framework can be further elaborated as follows:

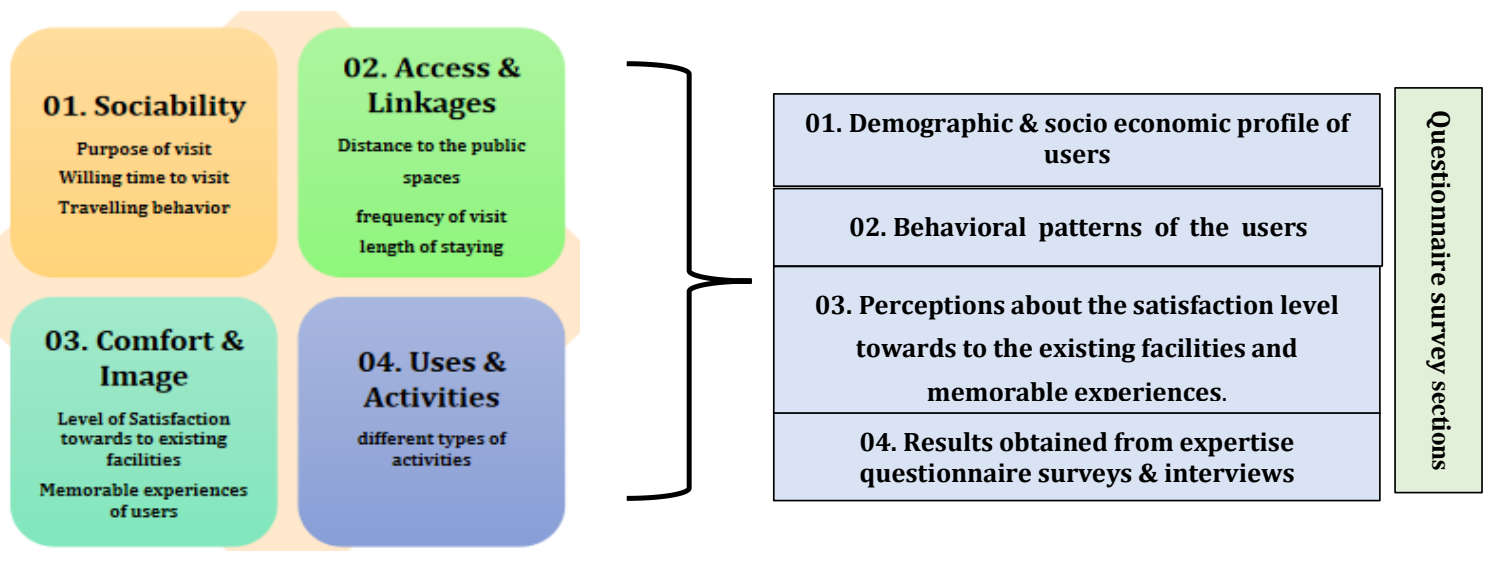

Figure 1; Four key attributes and the research framework

\section{Research Design}

\subsection{CASE STUDY DESIGN}

Case studies allow exploration of theories and provide opportunities understanding and in examining them at the ground (Baxter \& Jack, 2008).Therefore, in this study, three cases study areas were selected which are recently implemented, well known revitalized public spaces: Arcade independence square (AIS), Dutch hospital Colombo (DH) and the Race course (RC). In this study, the authors investigated qualities of these three places through the above four attributes.

\section{Data collection \& Analysis}

In order to address the research questions, this paper adopts perceptions from visitors who come to the above case study areas through online questionnaire surveys. The purpose of this questionnaire was to investigate the visitors' profile, socio economic information and their behavioral patterns. Therefore, in the first part of the questionnaire, to simplify the demographic and socio economic attributes. In the second 
part, behavioral patterns of the visitors were evaluated such as frequency of visit,purpose of visit, length of staying, visiting time and preferences to bring family members. The third part is to analyse the perceptions about the satisfaction level towards to the existing facilities and memorable experiences. Perceptions on satisfaction level towards to existing facilities were measured by using 1-5 Likert scale. Likert scale commonly used to measure attitudes,perceptions, and behavioral changes. Apart from that another online questionnaire was conducted for the field of expertise. In their questionnaire first part is to know about their profession, second part is to discuss opinions, perceptions, perspectives for Revitalization on development projects. Third part is to know about their professional relevance with urban revitalization projects for public usage. At the same time, by using interviews through telephone conversations and photovoice survey also helped to identify visitors perceptions, not only localities but also from foreigners. This research will investigate four attributes of public spaces based on users' perception.

Simple Random sampling technique has used to identify the respondents for this study. There were 103 participants as respondents. On the other hand, interviews were done by using online tools such as online questionnaires and interviews via phone calls, . In this regard, 10 online interviews were conducted with relevant authorities such as UDA, Archaeological department, Arcade and Dutch Hospital project officers etc. Further, 24 experts interviews were also conducted to understand their perceptions related to what things should be needed to improve within the Sri Lankan context of Revitalization and what are the barriers and challenges to these revitalized public spaces. Furthermore, five face to face interviews were conducted in site locations to explore suitable planning guidelines related to revitalization and project management drawbacks. On the other hand, a small photovoice survey was carried out by using the photos that reviewers have tagged within their comments in the Google pages related to three case studies. Thematic analysis and latent analysis were used for qualitative data analysis in this research and NVIVO software used to evaluate the results came out from expertise interviews and general public views regarding the perceptions on the quality of revitalized public spaces.

\section{Findings \& Results}

Within this section, it will be going to evaluate the results obtained from the questionnaire surveys and interviews with users and the expertise. Therefore, these results will be discussed through demographic \& socio economic data,behavioral patterns of users and perceptions towards to existing facilities and users memorable experiences. Other than these three parts, results obtained in the expertise interviews and questionnaires will be discussed. At the discussion section, it will be going to emphasize how these findings will be interconnected with the aforementioned four parameters of quality evaluation of revitalized public spaces.

\subsection{DEMOGRAPHIC \& SOCIO ECONOMIC PROFILE OF USERS}

As illustrated in Table 1 shows the data gathered regarding the descriptive findings of demographic data during the process of conducting the online questionnaire survey. Out of 103 respondents, $28 \%$ were male and $72 \%$ were females. Although this questionnaire survey was conducted via online majority of the respondents were at the 18-25 age category it was $62 \%$. especially there was not any respondents have counted under 60 years and above age group. Majority of the respondents $(75.7 \%)$ are unmarried and $24.3 \%$ are married respondents out of the total sample. On the other hand, their occupational status majority (51.5\%) are students and they are Diploma or Degree holders as a result of that most of respondents monthly income was recorded as below 2 lakh category (76.7\%) out of total sample. Overall, considering these demographic profile of the users it can be assumed majority of the respondents are at their teenage age and therefore, the above three cases are more else welcomed by the "youth community" but according to the authors, this study has used online survey so that most of elderly people were not have the ability to respond this questionnaire because they may have difficulty to access such online platform or they may be unfamiliar to respond. Table 1, shows the gender, education level, income, type of occupation influence the success of revitalized public spaces in attracting users. This finding is in conformity with Sangar (2007), who states that public spaces are places that are provided by public authorities and are shared by all people regardless of their personal, social and cultural differences.

\begin{tabular}{|c|c|c|c|c|}
\hline \multirow{2}{*}{ Demography } & Gender & Male & 29 & $28.20 \%$ \\
\hline & Age groups & From 18-25 years old & 64 & $62.10 \%$ \\
\hline
\end{tabular}




\begin{tabular}{|c|c|c|c|c|}
\hline & & From $26-44$ years old & 32 & $31.10 \%$ \\
\hline & & 60 years and above & 0 & $0 \%$ \\
\hline & Marital status & Unmarried & 78 & $75.70 \%$ \\
\hline & \multirow{2}{*}{ Ethnicity } & Sinhala & 92 & $89.30 \%$ \\
\hline & & Muslim & 5 & $4.80 \%$ \\
\hline \multirow{9}{*}{ Socio economic } & \multirow{6}{*}{ Occupation } & Government employed & 11 & $10.70 \%$ \\
\hline & & Private employed & 28 & $27.20 \%$ \\
\hline & & Self employed & 6 & $5.80 \%$ \\
\hline & & Retired & 1 & $1.00 \%$ \\
\hline & & Secondary education & 27 & $26.70 \%$ \\
\hline & & Diploma/Degree & 74 & $71.80 \%$ \\
\hline & & Below 2 lakh & 79 & $76.70 \%$ \\
\hline & Monthly income & 2 lakh - 5 lakh & 20 & $19.40 \%$ \\
\hline & & 5 lakh - 8 lakh & 4 & $3.90 \%$ \\
\hline
\end{tabular}

Table 1: Basic Demographic profile of the users

(Source: Online Questionnaire survey)

\subsection{BEHAVIORAL PATTERNS OF THE USERS}

Under the behavioral and patterns of the users followings can be identified as the aspects that affect the quality of the selected three cases such as frequency of visit,purpose of visit, length of staying, visiting time and preferences to bring family members.

\subsubsection{Purpose of visit}

During the survey, the respondents were asked about their purpose of visiting these three public spaces. Following bar graph (Figure 2) shows the findings why people come to these places and for what purposes. Therefore, in terms of "purpose" this study has found that the most important motivations of visit to these study areas by respondents are to chat with friends and relax. Moreover, the main purposes for visiting the DH, AIS and RC are, talking with friends, relaxation, having fun and spending time with their family.

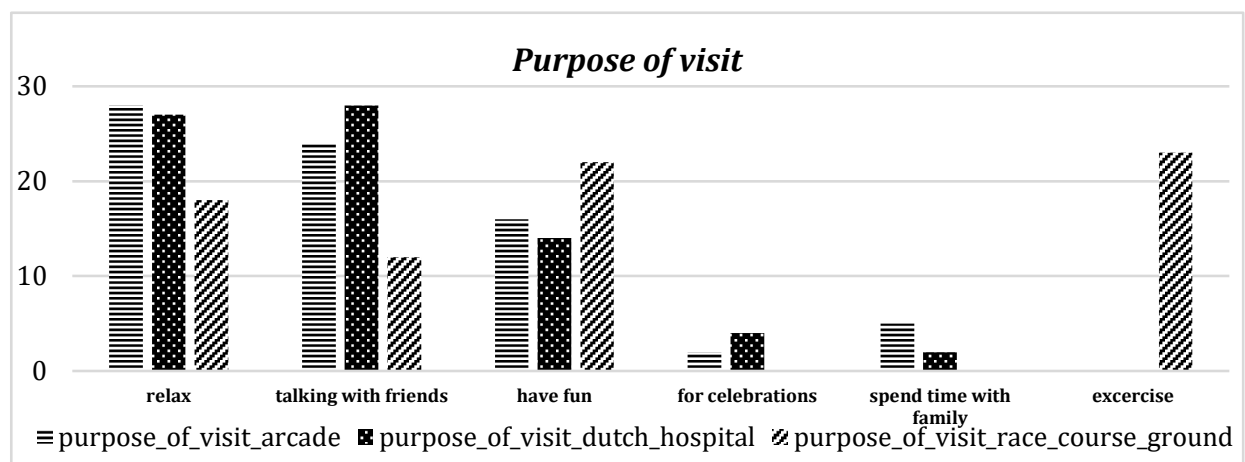

Figure 2, Purpose of visit three case studies

(Source: results obtained from the online questionnaire survey)

\subsubsection{Length of staying, Frequency of visit \& times of visit}

Following table 2, shows frequency of visit. According to the results, people who visit "everyday" they are the ones who live in the distance of "1-5 km" whereas the people who visit "rarely" or"sometimes" they are in the distance of "more than $30 \mathrm{~km}$ ". On the other hand, when the frequency of visit increases then the 
length of staying at these places also increased. Therefore, this gives some insight on the people's social networking within these places. Past literature also proved that "if people lose the chance of meeting with each other, they cannot develop common values such as tolerance, esteem and confidence which contribute to social networks. It is similar to the notion that most people prefer to have a good time with close friends rather than just meeting with a stranger Gehl (1996).

\begin{tabular}{|l|c|c|c||c|c|}
\hline \multicolumn{5}{|c|}{ Frequency of visit the arcade * staying hours at the arcade Cross-tabulation } \\
\hline & less than 1 hour & $1-2$ hours & $2-3$ hours & $3-4$ hours & more than 4 hours \\
\hline everyday & 0 & 0 & 6 & 0 & 4 \\
\hline \hline 2-3 times per week & 0 & 6 & 4 & 1 & 15 \\
\hline \hline once in a month & 3 & 8 & 9 & 0 & 1 \\
\hline once in a year & 0 & 2 & 2 & 0 & 1 \\
\hline \hline sometimes & 2 & 11 & 4 & 4 & 1 \\
\hline \hline rarely & 0 & 10 & 4 & 2 & 3 \\
\hline
\end{tabular}

Table 2: Results for frequency of visit three cases

(Source: results obtained from the online questionnaire survey)

The results showed that the frequency of visit arcade as 2-3 times per week is around 25\% where as respondents visit Dutch hospital once in a month is $34 \%$ and respondents frequency of visit Race course is rarely $47 \%$.

\subsubsection{Willing time to visit, Travelling behavior and Distance to the public spaces}

According to the respondents, from 12 p.m. to 2 p.m. was identified as their most willing time period to visit AIS (38.1\%) and DH (33.6\%), but for the RC 8 a.m. -12 p.m. and 2 p.m.-5 p.m. In terms of Behavioral patterns, table 4 shows, the majority travel with their families (42.70\%). In terms of individual places, for the Dutch hospital, the majority travel with their friends (46.60\%) and Race course playground area with friends (65\%). This shows these places are attracted by youth and they may offer some activities for them to spend time there.

\begin{tabular}{|c|c|c|c|c|}
\hline \multirow{12}{*}{$\begin{array}{l}\text { Travelling } \\
\text { Behavior }\end{array}$} & \multirow{4}{*}{$\begin{array}{l}\text { Travelling type } \\
\text { (Arcade) }\end{array}$} & With family & 44 & $42.70 \%$ \\
\hline & & With friends & 42 & $15.50 \%$ \\
\hline & & As a couple & 16 & $40.80 \%$ \\
\hline & & As an individual & 1 & $1.00 \%$ \\
\hline & \multirow{4}{*}{$\begin{array}{l}\text { Travelling type } \\
\text { (Dutch Hospital) }\end{array}$} & With family & 13 & $12.60 \%$ \\
\hline & & With friends & 48 & $46.60 \%$ \\
\hline & & As a couple & 33 & $32.00 \%$ \\
\hline & & As an individual & 8 & $7.80 \%$ \\
\hline & \multirow{4}{*}{$\begin{array}{l}\text { Travelling type } \\
\text { (Race course } \\
\text { playground) }\end{array}$} & With family & 18 & $17.5 \%$ \\
\hline & & With friends & 67 & $65.00 \%$ \\
\hline & & As a couple & 1 & $1.00 \%$ \\
\hline & & As an individual & 17 & $16.50 \%$ \\
\hline
\end{tabular}

Table 3: Travelling behavior of the users

(Source: results obtained from the questionnaire survey)

On the other hand, "distance to the place" and "frequency of visit"; results show that there is a very strong evidence of a relationship between distance to the place and frequency of visit those places: Arcade: (chi-square $=51.827, \mathrm{df}=15, \mathrm{p}<0.05$ ), DH: (chi-square $=29.949, \mathrm{df}=12, \mathrm{p}<0.05$ ) and RC: (chisquare $=27.857, \mathrm{df}=12, \mathrm{p}<0.05$ ). It reveals that when the distances are decreased then the frequency of visit to the places have been increased. 
Moreover, utterances came out from the interviews prove that when users visit these places with their close friends or close companionships then it automatically increases the intensity towards these places. As comments highlighted:

"For kids they can see the fish down the glassed tiled pond which we can walk over. Theater in the premises give another advantage to attract people."- local visitor-

"A great place to meet with friends and family or even on your own."-local visitor-

"A good place to hang out with your friends or loved ones with places to eat and shop around." - local visitor-

\subsection{PERCEPTIONS ABOUT THE SATISFACTION LEVEL TOWARDS TO THE EXISTING FACILITIES AND MEMORABLE EXPERIENCES.}

\subsubsection{Level of Satisfaction towards to existing facilities}

Other than the aforementioned findings, satisfaction levels towards facilities were measured because public facilities are important elements that need to be provided the public spaces. The result of the Relative Importance Index. Analysis on the perception of existing facilities or services in these selected public spaces are shown in Table 4,5 below.

$R I I=\underline{5 n_{5}}+4 n_{4}+3 n_{3}+2 n_{2}+1 n_{1}$ $A * N$

\begin{tabular}{|l|c|c|}
\hline \multirow{2}{*}{$\begin{array}{c}\text { Level of satisfaction on available facilities at } \\
\text { Selected case studies }\end{array}$} & \multicolumn{2}{|c|}{ Reliability Statistics } \\
\cline { 2 - 3 } Race course & Cronbach's Alpha & No of Items \\
\hline Arcade Independence Square & 0.944 & 16 \\
\hline Dutch Hospital & 0.934 & 14 \\
\hline
\end{tabular}

Table 4: Cronbach's Alpha for three cases- level of satisfaction on facilities (source:SPSS Reliability test)

Therefore, table 4 shows,the internal consistency among the level of satisfaction (LoS) factors that are highly reliable because in all three places their Cronbach's Alpha(CA) is more than 0.07 normally this reliability is ranging in between from " 0 " to " +1 ". This suggests that respondents' perceptions towards the LoS on the available facilities are in a good position although there are few drawbacks.. The results show that,satisfaction towards to the available facilities are high in RC is * $0.944>0.7$, and the least reliability can be identified for the facilities at the $\mathrm{DH}^{*} 0.873<0.7$. This indicates that the existing facilities need to be improved further. Therefore, with this finding it shows how users feel on the existing facilities with different perspectives.

Table 5, shows the results obtained for Arcade and how users satisfaction levels towards to the existing facilities based on RII analysis. Therefore, majority of users satisfied with the 1,2,3,4 \& 5 facilities, where users gave there dissatisfied values for $6,7 \& 8$ facilities that shown in the above table

\subsubsection{Memorable experiences of users}

Table 6 shows the results obtained from the Thematic analysis which is related to the Memorable experiences. The aspects that are needed to be in a public space and enhance the users' memorable experiences are also investigated within this study. 


\begin{tabular}{|l|c|}
\hline \multicolumn{1}{|c|}{ statements } & RII \\
\hline 1.Availability of monuments landmarks statues & 1 \\
\hline 2.Availability of CCTV cameras & 2 \\
\hline 3.Availability of safety areas & 2 \\
\hline 4.Availability of food shops restaurants & 3 \\
\hline 5.Availability of security officers & 3 \\
\hline 6.Availability of green spaces & 8 \\
\hline 7.Facilities for disable people & 9 \\
\hline 8.Availability of lighting & 10 \\
\hline
\end{tabular}

Highly satisfied Facilities

Dissatisfied Facilities

Table 5: Level of Satisfaction towards to the facilities in Arcade (Source: Relative Important Index)

\begin{tabular}{|l|l|c|c|c|c|}
\hline $\begin{array}{c}\text { Aspects that Place } \\
\text { making theory } \\
\text { emphasized }\end{array}$ & \multicolumn{1}{|c|}{ Themes } & $\begin{array}{c}\text { Reviews for } \\
\text { Race course }\end{array}$ & $\begin{array}{c}\text { Reviews for } \\
\text { Dutch Hospital }\end{array}$ & $\begin{array}{c}\text { Reviews for } \\
\text { Arcade }\end{array}$ & $\begin{array}{c}\text { Total } \\
\text { responses }\end{array}$ \\
\hline \multirow{2}{*}{ Social opportunities } & $\begin{array}{l}\text { Activities, functions and } \\
\text { events }\end{array}$ & 36 & 8 & 5 & 49 \\
\cline { 2 - 6 } & Food \& Restaurants & 12 & 32 & 15 & 59 \\
\hline \multirow{2}{*}{ Place quality } & Enjoy the place & 11 & 25 & 14 & 50 \\
\cline { 2 - 6 } & Historical values & 11 & 9 & 23 & 43 \\
\hline \multirow{3}{*}{ Physical form } & Architectural values & 3 & 9 & 13 & 25 \\
\cline { 2 - 6 } & Renovation of the Place & 25 & 3 & 26 & 54 \\
\hline
\end{tabular}

Table 6: Thematic analysis results

(Source: NVIVO software output)

According to the above table 6, it gives some insights about what are the most influential factors for creating pleasant or unpleasant memorable experiences of users. These findings indicate that users' memorable experiences in terms of social opportunities, place quality and physical form of these revitalized public spaces impact on creating positive or negative images towards a place according to the Placemaking concept. As an example, when consider about the Social opportunity theme there most of the users pay their attention towards to activities and functions happening these three places and food and restaurants these two things are really matter for having good or bad memorable experiences. Therefore, time and location tagged photographs, walk through videos and bitmap textures can be used when doing these types of analysis. On the other hand, with this sensory urbanism, "Memorable references" is one of the factors that we cannot ignore because in this study also comments, reviews and the perceptions of the respondents are really important to get an idea about these places and its quality so "the key to understanding places is our past place experiences. Memorable imagery is basic to architectural design and experiences are key to one's ability to make places" ("Sensory urbanism proceedings, 2008")

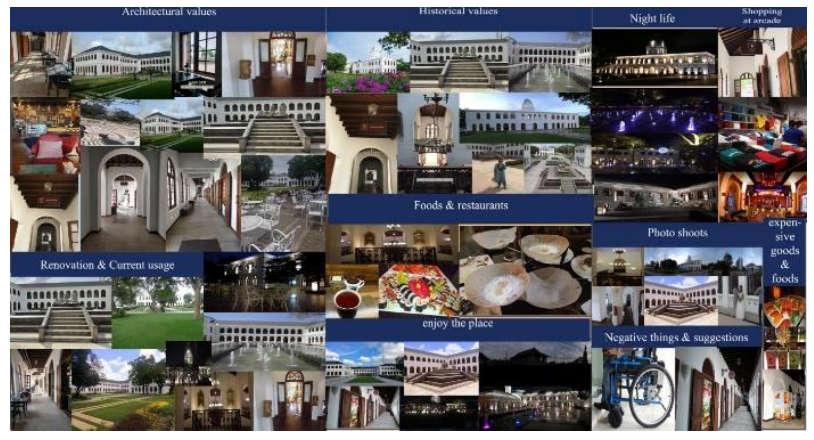

\begin{tabular}{|l|l|l|}
\hline $\begin{array}{c}\text { Photovoice } \\
\text { methods }\end{array}$ & No of data collected & \multicolumn{1}{|c|}{ Sources } \\
\hline $\begin{array}{l}\text { Online } \\
\text { reviews }\end{array}$ & $\begin{array}{l}\text { Arcade-60 } \\
\text { Dutch hospital - 60 } \\
\text { Race course - 60 } \\
\text { Total no. Of photos- } \\
180\end{array}$ & $\begin{array}{l}\text { Google reviews, } \\
\text { Trip adviser Sri } \\
\text { Lanka Expertise } \\
\text { at UDA (project } \\
\text { team members } \\
\text { for Dutch } \\
\text { hospital Race } \\
\text { course, and the } \\
\text { Arcade }\end{array}$ \\
\hline Observations & Take photos & On site photos \\
\hline
\end{tabular}

Figure 3, Photovoice survey results for Arcade Independence Square \& table shows photovoice data collection methods 


\title{
5.4. RESULTS OBTAINED FROM EXPERTISE QUESTIONNAIRE SURVEYS \& INTERVIEWS
}

Apart from the above findings, there was a questionnaire survey for expertise from different professions and they were asked to fill questions based on their experiences on revitalization projects that they have involved or worked, they were asked to give their suggestions to improve the revitalization process specially on public places and they were asked to discuss the weaknesses in the revitalization projects (based on 3 cases). Moreover, they were asked to emphasize the issues and the limitations within the Sri Lankan process of revitalization on public spaces as in the figure 5. According to the expertise followings are the suggestions for revitalization process for the adaptive reuse of historical buildings,

\begin{abstract}
Public awareness on Adaptive Reuse (AR) for historical buildings : When people are having well understanding of the adaptive reuse then it will make vast opportunities for a city to promote its legacy without any reluctance of the community.

Public \& Private partnership and the Government involvement :These projects are already identified as risky projects therefore it is better to have PPT model with this process but with the maximum intervention with Government because these places are really the reflections of our great history so as a country we all have that responsibility to protect it as much as possible best fit use.

Including this AR field as a concept for further studies to the relevant professions or the relevant educational level:Literature already identified that there is a lacking of skilled staff or the experts in this field of study in Sri Lanka so that it would be better that from our educational sector can involving with this process also.

Conducting continuous professional development programs and sessions: Up to now in Sri Lanka UDA has started these types of programs and training programs involving with other countries for their professional staff at the project division and the Research and Development (R\&D) division so it would be better that continue that process (ex: "Shared Cultural Heritage Program - 2019" Urban Heritage Strategies for Sri Lankan Professionals Held in Rotterdam, Erasumus (IHS) 2018)

Enhancing and improving the resources for conducting research and development on AR with modern technology :In Sri Lankan AR projects because most of the projects were failed due to lack of technical knowledge or lack of knowledge on modern technological methods in AR study field.
\end{abstract}

based on these suggestions, most of the time our revitalization techniques need to be improved and public awareness is a must whenever going to start such projects. On the other hand, project partnership and the government involvement are the two important things should be consider further within these types of risky projects. And they have said very correctly about the lacking of research and development on Adaptive reuse or Revitalization on historical buildings need to conduct further more. And that is one of the research gaps that authors also wanted to fill within this study . within the 10 interviews were carried with expertise they have given their insights and perceptions on the limitations within the revitalization process in Sri Lanka especially revitalization on historical buildings as in the three case studies. Following, figure 4 summarized what came up at the interview as challenges or limitations within our process;

\section{Social barriers \& challenges}

$>\quad$ Lack of public awareness about the revitalization and its adaptive reuse

$>$ Social reluctance to change the use of a historical building

$>\quad$ Political intervention to change the usage of the heritage building

$>\quad$ Do not have proper understand about the historical values of the particular place

$>$ Considering the demolition is the only alternative for change the usage of such historical places.

$>\quad$ Do not get the expected benefits from the restorative projects.

"Yes. Not getting expected Project benefits"- UDA Town planner

"Verv aood iob. but the taraet aroun should be middle income

Other barriers in the adaptive reuse

$>\quad$ Lack of knowledge in adaptive reuse on historical buildings therefore, it is better that including adaptive reuse as a discipline in the higher education programs.

$>\quad$ Conducting continuous professional development session with the collaboration of other related related institutions.

$>\quad$ After implementing the adaptive reuse projects there is a lack of getting feedback on that particular projects.

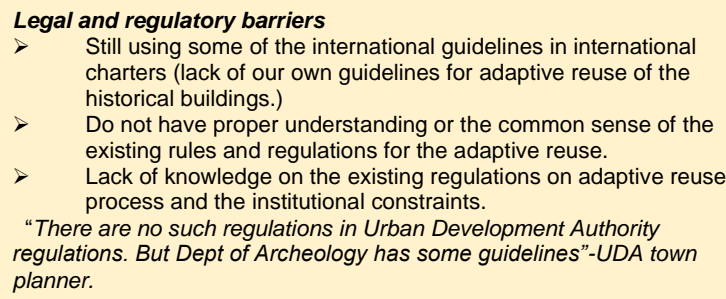

$>\quad$ Still using some of the international guidelines in international charters (lack of our own guidelines for adaptive reuse of the historical buildings.)

$>\quad$ Do not have proper understanding or the common sense of the existing rules and regulations for the adaptive reuse.

$>\quad$ Lack of knowledge on the existing regulations on adaptive reuse process and the institutional constraints.

"There are no such regulations in Urban Development Authority regulations. But Dept of Archeology has some guidelines"-UDA town planner.
Physical and technical and other related barriers
Restoration due to structural system layouts ("most of the time architectures have to deal with this problem very carefully.") Scarcity of required materials
Scarcity of required materials their adaptive reuse ("it is better to have some programs can be organized through responsible institutions for upgrading the adaptive reuse on historical buildings, for the project team before planning stage such as 'engage and share knowledge with international example adaptive reuse projects teams with corporation with UDA or other institutions")
Unavailability of proper structural and service drawings
$>\quad$ Unavailability of proper structural and service drawings. team, stakeholders for such adaptive reuse projects.

Figure 4: barriers or the challenges for revitalization process especially on historical buildings adapt their usage as a public place. 


\section{Discussion}

The main objective of this research study is to investigate what are the aspects that affect to improve the quality of revitalized public spaces. As for this purpose, authors have identified three cases that are very recently revitalized public spaces in Colombo. With the perceptions of its users and the relevant field of professional expertise, this research has improved to achieve the aim. As a result of that intention, through out the study, authors attempted to emphasize the above findings within the framework of four parameters such as 'sociability,access \& linkages,comfort \& image and activities \& uses' these four have been identified from the previous studies that carried out by different scholars from different countries but similar research areas. Moreover, here authors used these four parameters as their way findings or the road maps to identify the aspects which came up from the users point of views under the three sections within their questionnaire survey, such as 'Demographic \& socio economic details, behavioral patterns of the users and satisfaction level towards to the existing facilities \& memorable experiences' are the key areas that have focused within their questionnaire survey. As a result of that, within these three sections, authors could able to identified key aspects which are also coming up under the aforementioned four parameters also, those aspects can be identified as purpose of visit, frequency of visit, length of staying, travelling behavior, times of visit, basic demographic profile of users, level of satisfaction on existing facilities, users memorable experiences with these three cases have been identified as the key aspects that used to evaluate the quality of these three revitalized spaces according to the users perceptions apart from that authors have identified what are the expertise opinions and what are their thoughts on the limitations or the challenges towards to revitalization process in Sri Lanka also studied within this study. However, finally this study is important because Colombo as our capital city which contains great history behind this giant city, there are many archaeologically and historically important places in this big city but sometimes it is a question that why people cannot able to get any valuable usage out of those places without demolishing such historical pieces in the city and why we cannot adapted those places for a new usage which is suitable to the cities like Colombo and proudly conserve such places for future generations. Therefore, this study aims to wake up people's mindset about the ability to enhance and beautify a city while preserving the historical values behind that giant physical structures of a particular city while giving a unique character to its context.

\section{Conclusion}

As a conclusion, this study shows peoples' perceptions towards to the 'quality' of revitalizing public spaces and current adaptive reuse of these places. Moreover, this study goes beyond the past similar studies and highlighting people's perception is associated with the revitalized public spaces especially adaptive reuse in the historical buildings. Within this research authors could able to find out what are the field of expertise perceptions on these revitalized public spaces and based on their professional experiences they have given their valuable thoughts on what actually we are lacking behind instead of the revitalization process especially on historical buildings adaptive reuse in Sri Lanka along with the selected case studies.Those appear to be the specific contributions to fill the knowledge gap in this study. Still there are more to investigate on these four parameters sociability, access \& linkages, comfort \& image and activities \& uses for evaluate what users actually expected from revitalized urban public spaces because sample size is somewhat bias and due to the Covid situation questionnaire surveys carried out through online methods therefore, there may be having some issues with the sample size also. But future researchers who are interesting to improve this study further they can increase the sample size and investigate more on the above parameters. For the future researchers it will be useful to explore the economic valuation of historic buildings and the behavior of the property market and its impact on the adaptive re-use of historical buildings which, to our knowledge, have not been studied well. Public involvement is essential in adaptive re-use and management of historical properties if they are to be effective and sustainable in the long run so that this will be another research area for the future researchers.

\section{References}

Aghostin-sangar, V. ( 2007). Human behaviour in public spaces, Sydney, NSW.

Ahmed Z. Khan, Pieter Van den Broeck, Ruth Segers,Barbara Van Dyck, Bart Pluym. ( December 2016). Spatial Quality. Why, for Whom and According to Which Method? Retrieved form www.// researchgate.

Chandratilaka, W. N. (2011). Assessment of the Impacts of historical buildings on real estate development in Colombo Fort. Sri Jayewardenepura: DOI: 10.31357/fmscmst.2011.00176.

Cherchi, B. P. ( 253-270). Adaptive Reuse of Abandoned monumental buildings as a strategy for urban livability. Athens Journal of Architecture - Volume 1.

Clare L. \& uzzell.(n.d.). Place and process. Journal of Environmental Psychology (205-220). 
Maimunah, R.et al. ( 2015 ). Revitalization of Urban Public Spaces . Iran.

César,S,J, \& Laura,V. (2017). Restoration and the City: The roleof public urban squares. The Journal Frontiers in Psychology, 1-13.

Edirisinghe, J. (2014). Revitalizing the built heritage for urban development: A case study on city of Colombo, SriLanka. European academic research, 2286-4822. 